\title{
We CAN Fix Healthcare
}

\author{
Stephen K. Klasko, MD, MBA \\ Editor-in-Chief, \\ Healthcare Transformation; \\ President and CEO, \\ Thomas Jefferson University \\ and Jefferson Health
}
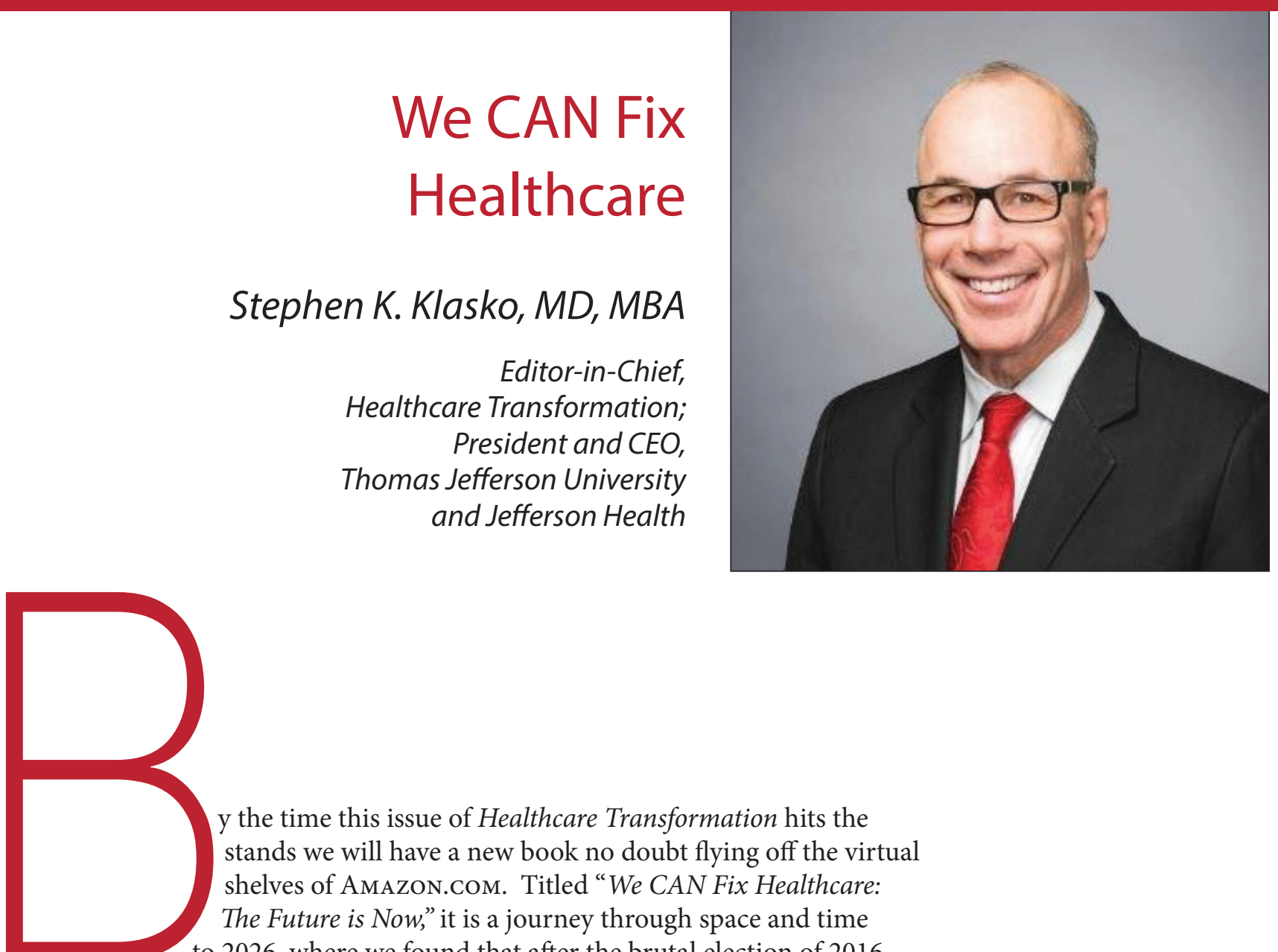

$y$ the time this issue of Healthcare Transformation hits the stands we will have a new book no doubt flying off the virtual shelves of Amazon.com. Titled "We CAN Fix Healthcare: The Future is Now," it is a journey through space and time to 2026, where we found that after the brutal election of 2016, Democrats and Republicans united around 12 disruptors that allowed us to create the ideal healthcare of the future.

Sounds impossible? Well, that's why we had to bend the space-time continuum and write a history of the future.

And why did we need 12 disruptors? Couldn't one or two have done it?

In short, healthcare needs a "new model" that makes the existing failed model obsolete.

\section{In short, healthcare needs a 'new model' that makes the existing failed model obsolete. 99} Obamacare, accountable care organizations, and bundled payments are all part of the new strategy, but as we enter the next fifteen years of the 21 st century, we are still getting "punched in the mouth" with rising costs, rising health disparities, and anger on both sides of the aisle. Yet, we are still told that it is "impossible" to fundamentally transform our complex, inefficient, expensive, inequitable and occasionally unsafe healthcare delivery system. Everyone-physicians, patients, pharmaceutical companies, employers, payers, policy makers, academic leaders, administrators, information technology vendors-they all say, "I'm trying to fix it. It's not me, it's them!" 


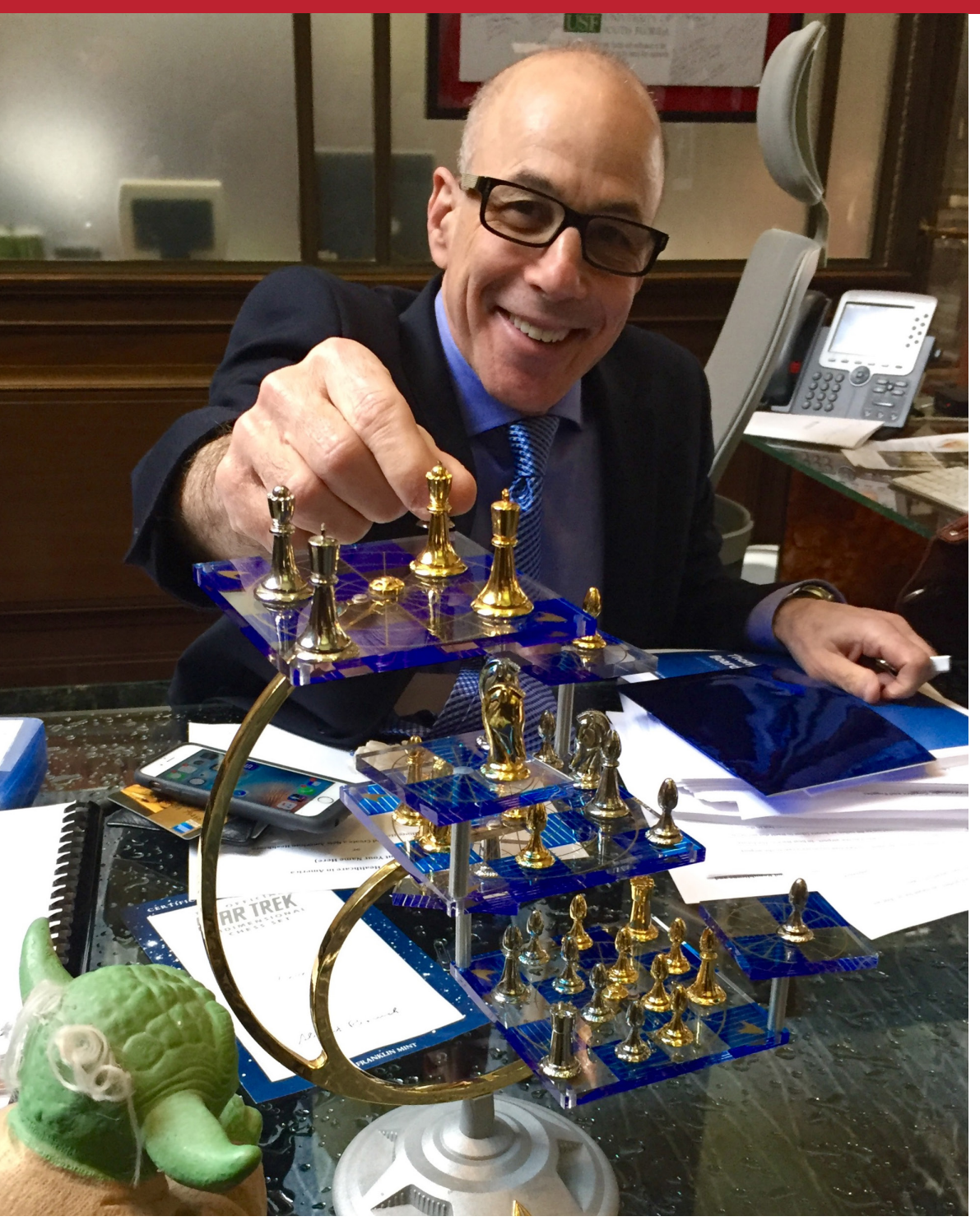

66 We don't presume that we are the smartest people in the room. We think that we are more than smart enough and experienced enough to make a contribution at an important time...99

So, why another book on healthcare in America? Bookshelves and search engines overflow with them. The topic matters to us individually and collectively, but why add to the pile? Actually, we think this book differs from most of the pile in several notable and, we would argue, useful ways.

First, we don't presume that we are the smartest people in the room. We think that we are more than smart enough and experienced enough to make a contribution at an important time, but we don't think or write, either explicitly or implicitly, as if everyone else should just shut up, sit down, and do what we say. We don't think that others need only to follow us to find healthcare nirvana, nor are we angry that they haven't. We think we have something to say that could help, and yet we don't take ourselves too seriously to play a bit in the process of saying it-a spoonful of sugar and all that. This stance on our part, we believe, allows a broader, fuller look at healthcare in America and a more enjoyable read.

Second, we firmly believe that the key word in the phrase "the system of healthcare in America" is the word "system." Our country has evolved an overall 

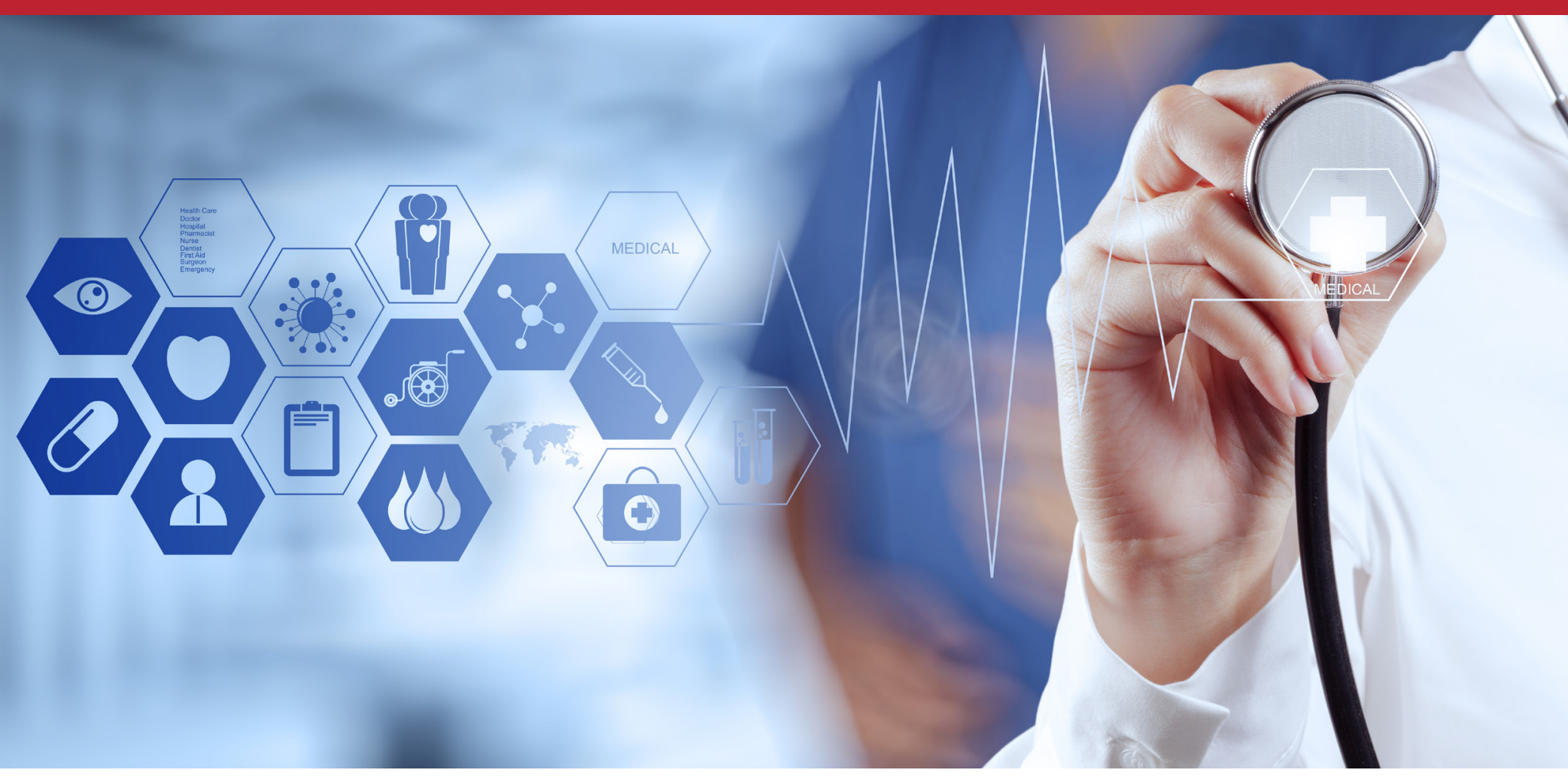

approach to healthcare. We've built it over time and, while it's not pretty to look at in its entirety, in its "system-ness", it all fits together. Our system of healthcare, like any system, delivers what it is designed to deliver. Hence, to produce something else, such as better outcomes and better care for less cost, for instance, requires stepping back and looking at the system as a whole. To change a part and thereby to expect system change probably stems from either naiveté or cynicism. In either case, failure to address the whole leads to changing only a part (which produces minimal if any change in the whole.) We look at the system as a whole in this book. We then use that lens when considering the component parts and their interconnection. That perspective makes this book different as well.

\section{If one wants to change the healthcare system in America, then three things need to happen. 99}

Even looking at the whole, let alone changing it, has proved frustrating and repeatedly difficult. Too often people try to fix one piece. Looking at the healthcare system as a whole inevitably triggers opposition. Yet, how one looks serves to determine how one sees (to paraphrase RD Lang), and how one sees determines how one acts. In the case of change, the way of looking at it models the change you get.

If one wants to change the healthcare system in America, then three things need to happen:

The values behind our book:

1. We need to examine the whole system objectively. As a physician, you would not treat a patient based on indirect examination, innuendo, or a sense of inevitable failure. 
2. We need to look in the mirror. It is way too easy to absolve yourself, no matter what your role in the system, whether Democrat or Republican, provider or patient, employer or insurer. You own it-its successes and its failures.

3. Do or do not, there is no try. Yoda had it right. As we approach yet another election cycle, it is time to decide whether we are willing to disrupt the system fundamentally or resign ourselves to what we have. Incremental "mission accomplished" changes just serve to move the blade in the wound, prolonging the agony.

President Obama provided painful confirmation of the previous paragraph. His campaign included a pledge that he would redesign America's healthcare system by putting the key stakeholders, representatives of all of them, in a room and have them work through the matter on C-Span for all to see.

Brilliant.

Lay out (expose?) the system to one and all and in so doing educate all of us as policymakers, providers, and patients to embed a system-wide approach to system-wide change.

Brilliant.

One problem. It didn't happen. Doors closed. Side deals and 66 As we approach yet another election cycle, it is time to decide that we are willing to fundamentally disrupt the system or resign ourselves to what we have. 99 sub-optimization reigned yet again. Lots of froth and frenzy begot, thus far, minimal change in desired outcomes such as actual, aggregate, affordable access to improved healthcare. The process augured the result. Hence, the authors seek to go back to what President Obama did not do in order to go forward. What if he had assembled those stakeholders? What if he did it before he left office? What if his successor chose to go back to go forward? Doing so would have differentiated Obamacare and does differentiate this book.

Third, we remain optimistic. We wrote The Phantom Stethoscope: A Field Manual for an Optimistic Future in Medicine (Klasko and Shea, 1999) in order to identify challenges facing physicians who wished to shape the future of medicine and to support them in that work. We have had the exceptional opportunity over the intervening decade and a half to work with physicians and other healthcare providers along with many other healthcare stakeholders to do just that. That work and those people have improved healthcare outcomes and lowered its cost to the great satisfaction of patients and providers alike. We know therefore that people can make healthcare fundamentally better and not just in a moment, however important a moment might be, but over time. We have seen it. Time and time again.

America has all the ingredients necessary to provide better, cheaper healthcare. It needs chefs who are willing to do, not try. 


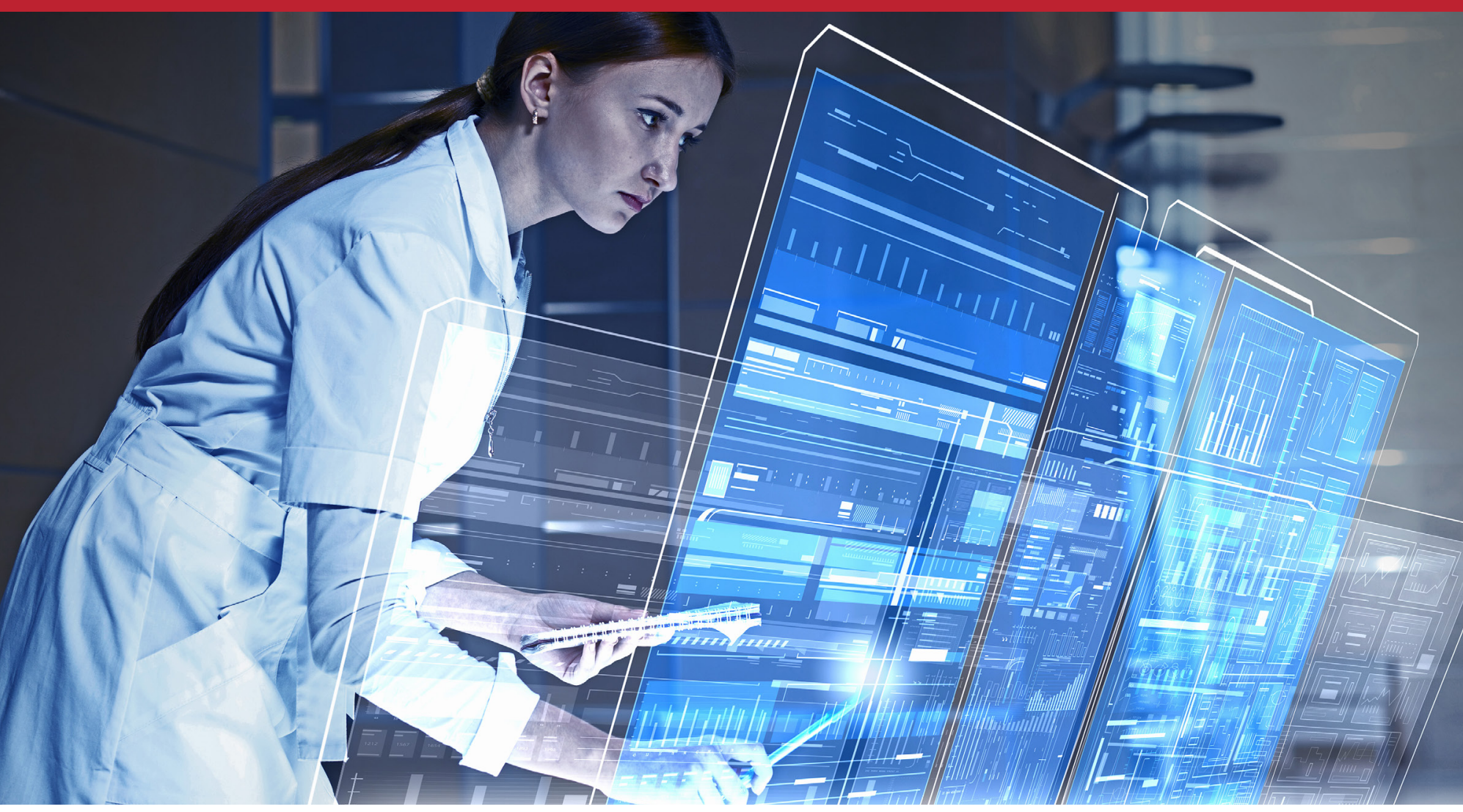

This is the second book after Phantom Stethoscope in which the authors have utilized a science fiction/history of the future approach. These techniques free the author and the reader of non-creative constraints. They also rest upon the assumption that an alternative and desired future can exist and that one can achieve it. History of the future advocates 'begin with the end in mind'. As a result, planners can use a disciplined step-by-step backward walk from the future to the present.

It's also a lot more fun to write and, hopefully, to read. These techniques can transport a reader to another vantage point, to one freer of limits, filters, and biases of our current moment. Such transportation can free the mind to consider new possibilities or options. It can also lead to discovery of an energy source for change: excitement born of envisioning a better world.

So, to quote Yoda again. "Difficult to see. Always in motion is the future."

In that vein, may the fours be with you:

1. Affordable, accessible healthcare regardless of race, religion, or pre-existing conditions.

2. Training the providers of the future, not the past.

3. Allowing healthcare to join the consumer revolution.

4. Alignment of incentives and creative partnerships between patients and providers based on improvement of health individually and collectively.

Here's to realizing an optimistic future in American healthcare for all of us, our children, and their children!

May the fours be with you! HII 